\title{
MODEL PEMULIHAN EKONOMI KELUARGA: SOLUSI BAGI PENYINTAS BENCANA TSUNAMI SELAT SUNDA DI PROVINSI BANTEN
}

\author{
Bambang Dwi Suseno'; Febi Almafutra ${ }^{2}$ \\ 1)Program Studi Magister Manajemen PPS Universitas Bina Bangsa; \\ ${ }^{2}$ Mahasiswa Program Studi Magister Manajemen PPS Universitas Bina Bangsa \\ ${ }^{1}$ e-mail: bambangds_mm@binabangsa.ac.id
}

\begin{abstract}
The tragedy that struck Banten Province at the end of 2018 which hit the coast of the South Coast, has resulted in a tsunami disaster. The disaster resulted in 437 casualties, and resulted in damage to houses and vital facilities commonly used by the surrounding community, in the form of hotels, houses, boats, shops and stalls as business capital. This paper aims to illustrate that reconstruction efforts can provide an opportunity to reduce the effects of future disasters by improving construction quality, avoiding hazardous locations, and increasing community awareness and preparedness. Post-disaster reconstruction can offer opportunities for improvement and for correcting old problems: to upgrade infrastructure, create new land use arrangements, improve construction and design standards, reinvent the economy, and improve governance. The PKM activities that have been implemented have succeeded at least in reviving economic sector businesses, by utilizing local potentials, which are useful to simply restore the spirit of life of the victims, especially in the coastal districts of Cinangka District, Serang Regency.
\end{abstract}

Keywords: Natural Disasters, Tsunamis, Reconstruction, Economic recovery

\begin{abstract}
Abstrak
Tragedi yang dialami Provinsi Banten pada akhir tahun 2018 yang menerpa pesisir Pantai Selatan, telah mengakibatkan Bencana tsunami. Bencana tersebut mengakibatkan 437 korban jiwa, dan mengakibatkan kerusakan rumah dan fasilitas vital yang biasa dipakai masyarakat sekitar, berupa hotel, rumah, perahu, toko dan warung-warung sebagai modal usaha. Tulisan ini bertujuan untuk menggambarkan upaya rekonstruksi dapat memberikan kesempatan untuk mengurangi efek bencana di masa depan dengan meningkatkan kualitas konstruksi, menghindari lokasi berbahaya, dan meningkatkan komunitas kesadaran dan kesiapan. Rekonstruksi pascabencana dapat menawarkan peluang untuk perbaikan dan untuk memperbaiki masalah lama: untuk memperbarui infrastruktur, membuat pengaturan penggunaan lahan baru, meningkatkan standar konstruksi dan desain, menemukan kembali ekonomi, dan meningkatkan tata kelola. Kegiatan PKM yang telah dilaksanakan telah berhasil setidaknya menghidupkan kembali usaha-usaha sektor ekonomi, dengan memanfaatkan potensi-potensi lokal, bermanfaat untuk sekedar mengembalikan semangat hidup para korban khususnya di pesisir Kecamatan Cinangka Kabupaten Serang.
\end{abstract}

Kata kunci: Bencana Alam, Tsunami, Rekonstruksi, pemulihan Ekonomi

\section{PENDAHULUAN}

Bencana alam merupakan suatu kejadian yang diakibatkan oleh peristiwa alam yang tidak dapat dihindari dan berdampak besar bagi penghidupan masyarakat pasca bencana. Peristiwa Tsunami yang menerjang wilayah pesisir Provinsi Banten pada 22 Desember 2018 telah menyisakan berbagai pekerjaan besar bagi semua pihak terkait. Gelombang tinggi

\footnotetext{
${ }^{1}$ Dosen Tetap Program Pasca Sarjana Universitas Bina Bangsa

${ }^{2}$ Mahasiswa Program Pasca Sarjana Universitas Bina Bangsa
} 
Tsunami yang diyakini karena letusan Gunung Anak Krakatau akibat tanah longsor di bawah laut tersebut telah menyisakan duka bagi banyak pihak. Badan Nasional Penanggulan Bencana (BNPB) mencatat hingga 2 Januari 2020, tim evakuasi telah mengidentifikasi dan memakamkan 429 jenazah dari 437 korban tewas akibat Tsunami di Selat Sunda. Sedangkan, korban luka dinyatakan mencapai 1.459 orang dan hilang sebanyak 10 orang.

Pasca Tsunami diperkirakan terdapat 36.923 orang sempat mengungsi dari tempat tinggalnya. Catatan lain BNPB, Tsunami selat sunda menyebabkan kerusakan hunian masyarakat dan fasilitas umum. Dengan rincian 2.752 rumah, 92 penginapan, 150 perahu dan kapal dinyatakan rusak. Diprediksi nilai kerugian akibat bencana Tsunami Selat Sunda mencapai Rp. 304 triliun.

Bencana besar bisa mengubah masa depan sebuah kota atau wilayah - baik atau buruk. Banyak contoh mengenai hal ini; Chicago dan San Francisco menjadi kota yang lebih sukses setelah itu dihancurkan oleh api dan gempa bumi. Contoh lain Kota Tokyo berhasil selamat dari kebakaran dahsyat akibat gempa bumi dan tsunami perang. Namun demikian terdapat juga contoh kota/daerah yang terpuruk , seperti kota Managua, Nikaragua, tidak pernah pulih dari gempa bumi tahun 1972. Kemudian Galveston,

Di negara bagian Texas,Amerika Serikat, kehilangan relevansinya sebagai pelabuhan utama AS setelah dihancurkan oleh badai besar pada tahun 1900. Proses pemulihan adalah aspek utama dari bencana, dan pengelolaannya sangat memengaruhi warga. Seperti itu malapetaka mengganggu kehidupan dan bisnis, sebagai manusia menunggu bantuan, perbaikan infrastruktur, dan pengembalian kehidupan dengan tetangga mereka. Manajemen masalah pemulihan karena efek samping dari bencana meluas membutuhkan waktu yang panjang (Johnson dan Olshansky, 2016).

Pada kondisi rekonstruksi dapat memberikan kesempatan untuk mengurangi efek bencana di masa depan dengan meningkatkan kualitas konstruksi, menghindari lokasi berbahaya, dan meningkatkan komunitas kesadaran dan kesiapan. Jika kita amati hanya ada sedikit pemahaman sistematis tentang cara membuat pemulihan bekerja. Saat bencana bencana melanda, para pemimpin yang terkena dampak masyarakat sering menyadari bahwa mereka pengalaman yang dikurangi relevan pengalaman, jadi mereka mencari pelajaran dari orang lain.

Dalam 40 tahun terakhir, sejumlah internasional serius bencana membutuhkan skala besar dan intervensi berkelanjutan oleh berbagai tingkat pemerintahan dan organisasi nonpemerintah. Di kami dunia global, masyarakat semakin diuntungkan dari bantuan mereka yang memiliki pengalaman baru dengan bencana di tempat lain. Mengingat ini terus berkembang kumpulan pengalaman pemulihan, waktunya sudah matang untuk mengatur dan mensintesis pelajaran umum. Kita sekarang punya cukup contoh untuk dikembangkan yang bisa ditransfer teori tentang proses membangun kembali permukiman manusia setelah bencana.

Pemulihan sebagai Proses Rekonstruksi Mengikuti Bencana oleh Haas, Kates, dan Bowden (1977), adalah studi pertama yang mengambil komprehensif, pandangan jangka panjang dari pemulihan bencana. Ini berfokus pada membangun kembali kota-kota San Francisco, California; Anchorage, Alaska; dan Managua, Nikaragua setelah gempa bumi tahun 1906, 1964, dan 1972, masing-masing. Para penulis mengusulkan pemulihan itu berkembang 
melalui empat yang berbeda tetapi tumpang tindih periode — darurat, pemulihan, penggantian rekonstruksi, dan rekonstruksi besar yang melibatkan perbaikan dan peringatan (gambar 1).

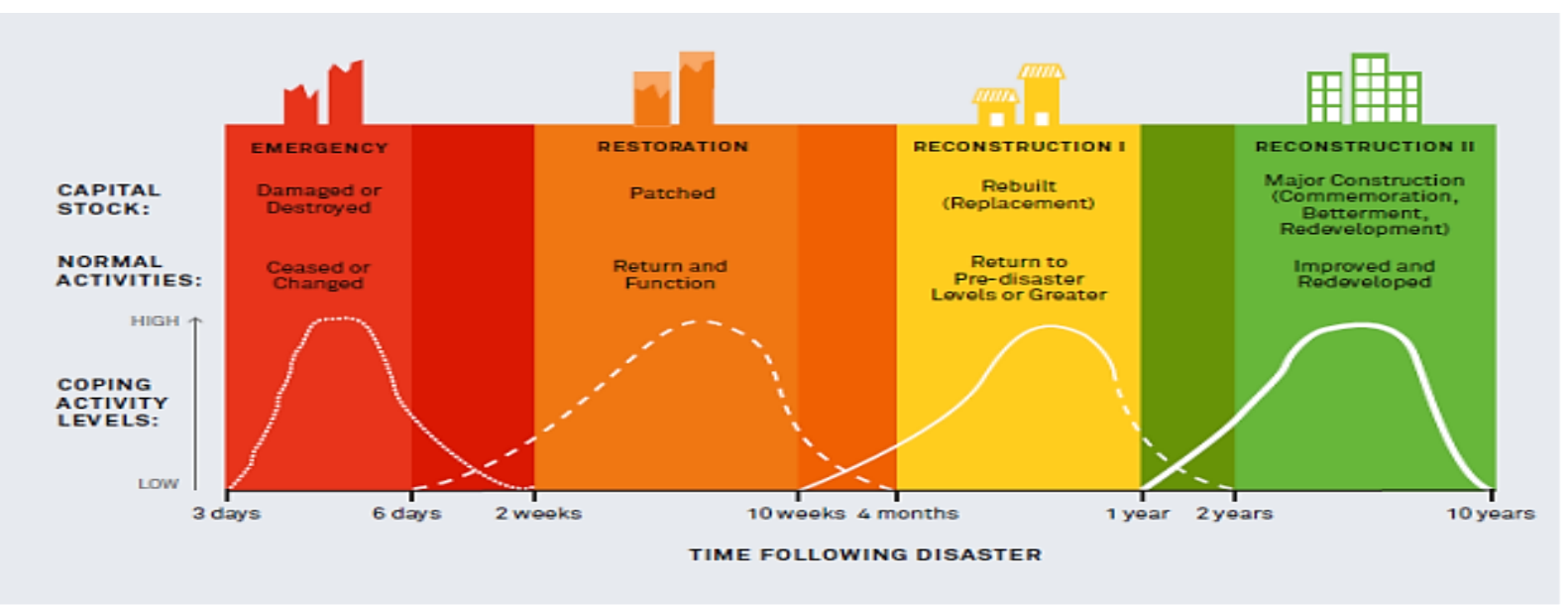

Gambar 1

Model Periodesasi Pemulihan Bencana

Sumber: Haas, Kates, dan Bowden (1977)

Dalam konteks bencana tsunami Sunda, diwilayah Kabupaten Serang, lebih banyak orang selamat dari bencana awal tetapi kemudian menderita dari pemulihan karena ekonomi mandek, jaringan sosial melemah, dan perawatan dan dukungan kesehatan layanan menurun. Pemulihan fisik dari bencana membutuhkan waktu bertahun-tahun dan luka psikologis bisa bertahan lama selama beberapa dekade. Rekonstruksi pascabencana dapat menawarkan peluang untuk perbaikan dan untuk memperbaiki masalah lama: untuk memperbarui infrastruktur, membuat pengaturan penggunaan lahan baru, meningkatkan standar konstruksi dan desain, menemukan kembali ekonomi, dan meningkatkan tata kelola. Laporan hasil studi tahap I yang telah selai dikerjakan oleh kelompok peneliti di Sekolah Tinggi IImu Ekonomi Banten, dimaksudkan sebagai identifikasi masalah yang nanti akan diintervensi dengan program pengabdian masyarakat (PKM) dimana para mahasiswa dan dosen akan menyusun program dan implementasinya sampai dengan pendampingan kepada kelompok dan masyarakat di wilayah Kecamatan Cinangka Kabupaten Serang.

\section{METODE}

Pengabdian Pada Masyarakat (Atau biasa disingkat PKM) adalah salah satu pelaksanaan Tri Dharma Perguruan Tinggi (pendidikan, penelitian, dan pengabdian kepada masyarakat). Kegiatan ini bersifat intrakurikuler, dilakukan dengan cara memberikan kepada mahasiswa pengalaman belajar dan bekerja dalam kegiatan pembangunan masyarakat sebagai wahana penerapan dan pengembangan ilmu serta teknologi. Dilaksanakan di luar kampus dalam waktu mekanisme kerja dan persyaratan tertentu.

PKM merupakan kegiatan yang berhubungan dengan berbagai disiplin ilmu dan berkaitan dengan berbagai sektor pembangunan. Dengan demikian pendekatan yang 
digunakan adalah pendekatan interdisipliner dan lintas sektoral. Kegiatan dan pengelolaan PKM dapat menjamin diperolehnya pengalaman belajar kongkrit yang bermanfaat bagi mahasiswa dan masyarakat dimana mereka ditempatkan. Selain itu, kegiatan dan pengelolaan PKM diarahkan untuk menjamin keterkaitan antara dunia akademik teoritik dan dunia empirik.

Sesuai bidang keilmuan Pasca Sarjana Universitas Bina Bangsa, kegiatan PKM diarahkan pada kegiatan ekonomi dari potensi yang lokal yang ada dikembangkan dan diberdayakan menjadi kegiatan ekonomi kreatif. Potensi lokal yang hendak diberdayakan adalah potensi wilayah yang dimiliki, dilakukan secara bersama antara mahasiswa dengan masyarakat.

Tema PKM 2020, yaitu Peningkatan Kompetensi Dan Empati Mahasiswa Melalui Pemulihan Ekonomi Keluarga Pasca Tsunami Selat Sunda. Program disusun dengan mempertimbangkan potensi, permasalahan dan kebutuhan daerah kerja PKM serta disesuaikan dengan bidang keahlian mahasiswa secara terintegrasi antar bidang keahlian. Pada program PKM ini mahasiswa diharapkan dapat mengamalkan ilmu pengetahuan, menitikberatkan pada bidang keahlian mahasiswa yaitu manajemen dan akuntansi, menyesuaikan misi Program Pasca Sarjana Universitas Bina Bangsa, meningkatkan sikap, pengetahuan dan ketrampilan mahasiswa, membantu pemerintah dalam pembangunan di daerah kerja serta memberikan manfaat bagi masyarakat dengan mempertimbangkan program-program pembangunan yang telah, sedang dan yang akan dilaksanakan.

Daerah terpilih adalah daerah yang terdampak Tsunami di pesisir Selat Sunda di wilayah Serang dan Pandeglang, meliputi Kecamatan Carita, Labuan dan Cinangka. Di kecamatan Carita terpilih desa Sukarame, Sukajadi, Carita dan Sukanegara. Di kecamatan Labuan, terpilih desa Teluk, Caringin dan Cigondang. Dan di kecamatan Cinangka terpilih desa Bulakan, Umbul Tanjung dan Karang Suraga. Semuanya terbagi menjadi 10 kelompok. Laporan ini merupakan laporan dari kelompok VI, yaitu desa Caringin, kecamatan Labuan, kabupaten Pandeglang.

Pada laporan ini, model pemulihan yang ditargetkan mencoba untuk secara umum menangani situasi yang tidak diinginkan dengan menentukan klasifikasi bencana. Setiap efek dianalisis dalam dua fase: (a) pra-bencana dan (b) pasca bencana.

\section{HASIL DAN PEMBAHASAN}

Dari hasil pelaksanaan Pengabdian Pada Masyrakat (PKM) tahun 2020 di Desa Caringin, Kecamatan Labuan, Pandeglang Banten yang dilaksanakan selama satu bulan, dari tanggal 29 Juni sampai dengan 28 Juli 2020. Dengan ini kami akan membahas program kerja yang telah dilaksanakan.

PKM 2020 merupakan kegiatan yang diprogramkan untuk pengabdian dosen dan mahasiswa terhadap masyarakat. Sebagian besar kegiatan terpusat di area lingkungan Desa Caringin. Program tersebut meliputi 3 bidang, Bidang Perekonomian, Bidang Peternakan, dan Bidang Pertanian. 
Adapun sarana dan prasarana yang kami susun sebelum melaksanakan PKM di Desa Caringin, Desa Caringin, Kecamatan Labuan, Pandeglang Banten adalah sebagai berikut :

1. Kegiatan Terlaksana

Semua kegiatan yang direncanakan dapat terlaksanakan dengan baik meskipun dalam pelakasanaannya beberapa kegiatan tidak terlaksana sesuai dengan jadwal perencanaan. Hal ini dikarenakan dengan penyesuaian jadwal kegiatan masyarakat. Kegiatan-kegiatan yang terlakasana antara lain :

a. Bidang Perekonomian

1. Warung Sahabat Program Pasca Sarjana Universitas Bina Bangsa

Warung sahabat Program Pasca Sarjana Universitas Bina Bangsa adalah salah satu program kerja prioritas kami, warung sahabat ini kami berikan kepada pihak Bumdes (badan usaha milik desa) Desa Caringin untuk dikelola secara bertahap sesuai anggaran yang telah diberikan oleh pemerintah pusat, tata pengelolaan yang diterapkan seperti sistem pengelolaan keuangan warung melalui laporan kas setiap bulannya. Hal ini bertujuan untuk peningkatan perekonomian desa melalui UKM Warung Sahabat Program Pasca Sarjana (PPS) Universitas Bina Bangsa (Uniba).

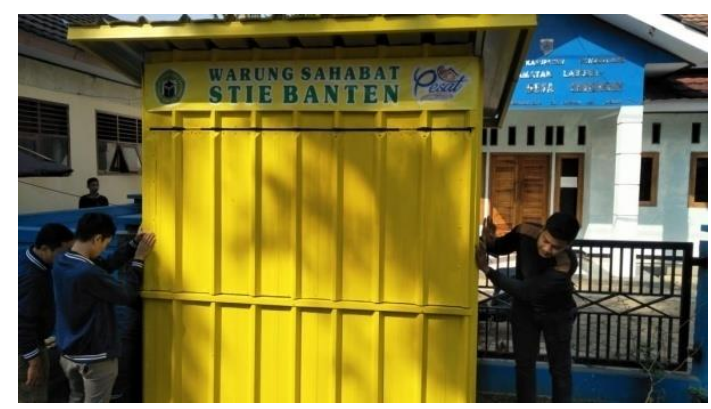

Gambar a.1.1.4

Warung Sahabat PPS Uniba

2. Produk Lokal

Produk lokal adalah salah satu program kerja tambahan, program kerja ini dititik beratkan pada proses produksi dan promosi produk unggulan milik Desa Caringin dan Pangulon, kedua Desa ini memproduksi produk unggulan seperti : Kue Apem, Opak Meletek, Rempeyek Udang, dan Emping Kecimpring. Tujuan dari program ini harap besarnya mampu membawa produk unggulan lebih dikenal oleh wisatawan yang datang sebagai oleh-oleh atau jajanan khas Desa Caringin dan Pangulon. 


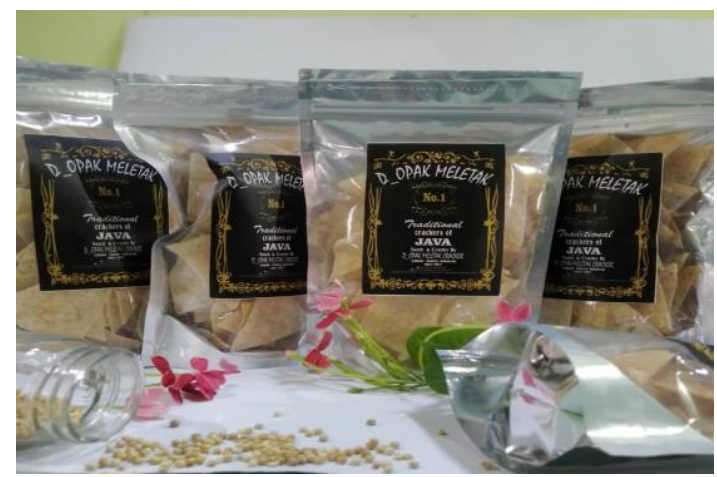

Gambar 2

Produk Lokal, D'Opak Meletak

b. Bidang Peternakan

1. Itik Ayam Kampung

Itik Ayam Kampung adalah salah satu program kerja prioritas, program kerja ini dititik beratkan pada proses pengembangbiakan hingga proses perawatan secara berkala, itik ini kami serahkan kepada pihak karang taruna desa untuk di kembang biakan yang bertujuan untuk peningkatan mutu ekonomi keluarga.

Program ini merupakan terusan dari program Kementerian Pertanian yang mencangkan program peningkatan kesejahteraan masyarakat berbasis pertanian. Dalam kegiatan ini, Universitas Bina Bangsa mendapatkan bantuan berupa DOC Ayam KUB unggulan Balitbang.

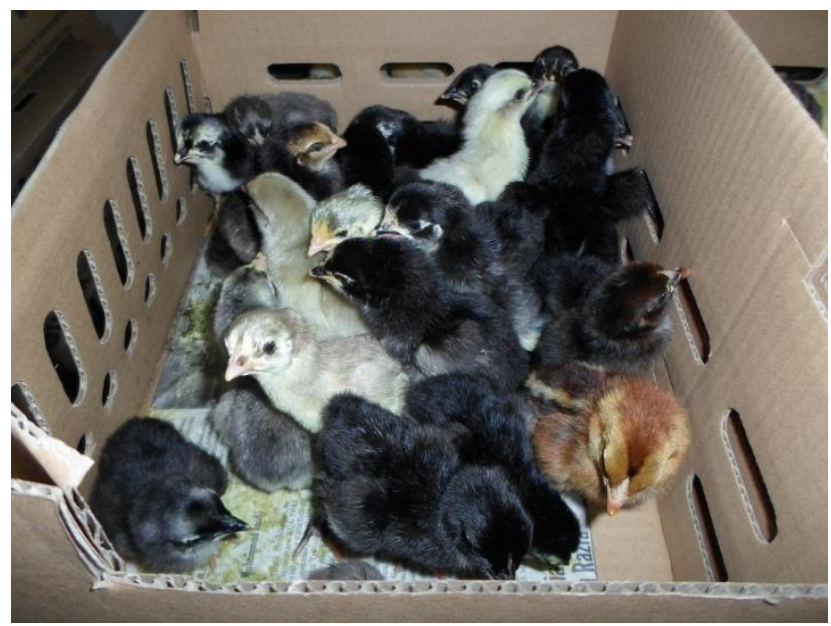

Gambar 3

Ayam KUBA

c. Bidang Pertanian

1. Penanaman Benih Sayur Di Pekarangan Rumah Warga 
Penanaman Benih sayur adalah salah satu program kerja prioritas, program yang dititikberatkan pada proses penyemaian hingga proses perawatan sampai membuahkan hasil yang diinginkan, program ini bertujuan agar masyarakat desa dapat membudidayakan dan memanfaatkan lahan perkarangan rumah, yang nantinya dapat dikonsumsi dan diperjual belikan.

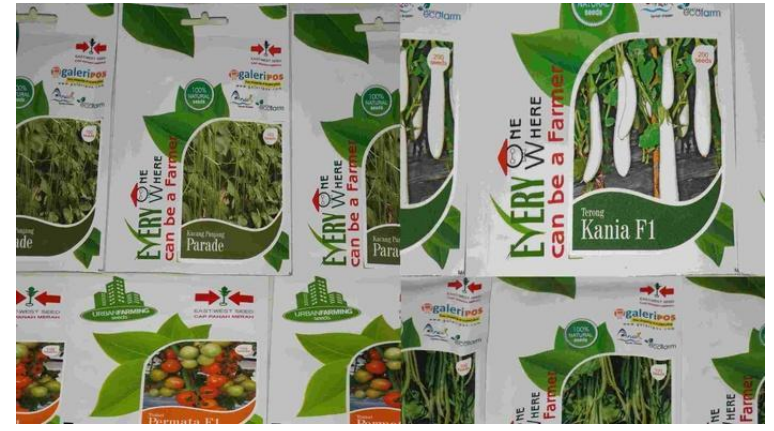

Gambar 4

Benih Sayur

2. Penanaman Bibit Pohon Mangga dan Manggis

Penanaman bibit mangga dan manggis adalah salah satu program kerja prioritas, program yang dititik beratkan pada proses penyemaian hingga proses perawatan sampai membuahkan hasil yang diinginkan, program ini bertujuan agar masyarakat desa dapat membudidayakan dan memanfaatkan lahan perkarangan rumah, yang nantinya dapat dikonsumsi dan diperjual belikan.
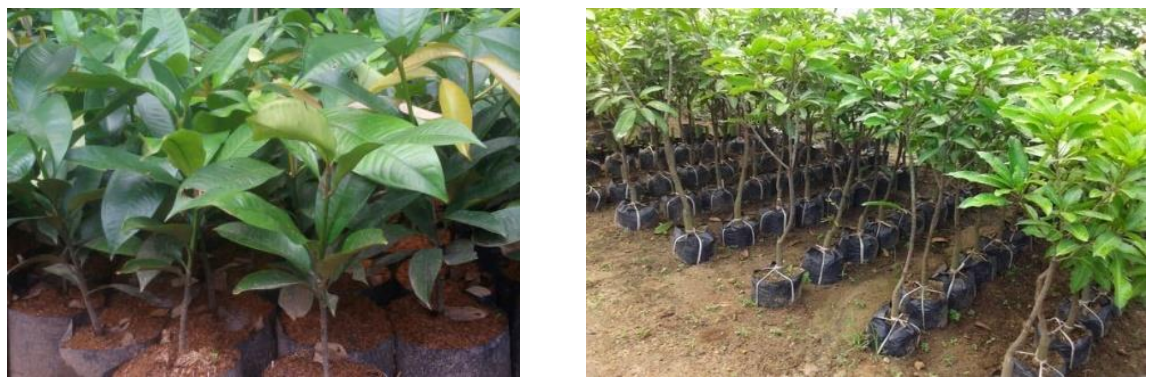

Gambar 5

Bibit Super Mangga dan Manggis

d. Bidang Kebersihan Lingkungan

1. Kerja Bakti

Kerja Bakti adalah salah satu program kerja tambahan, program yang dititik beratkan pada kebersihan lingkungan, program ini bertujuan agar masyarakat desa sadar akan pentingnya kebersihan lingkungan sekitar dan membudayakan budaya gotong royong sebagai ajang silaturahmi antar warga. 


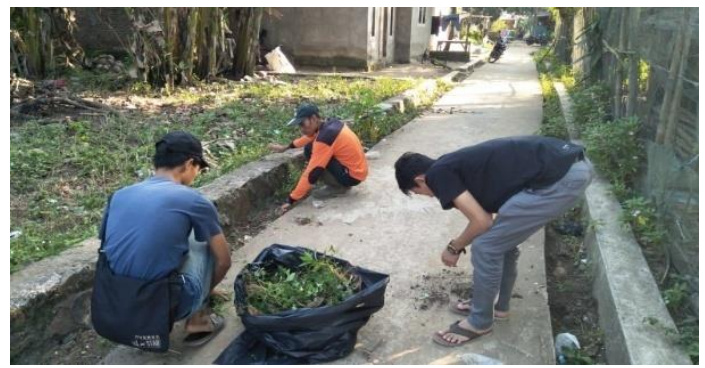

Gambar 6

Kerja Bakti Bersama Warga Desa

e. Bidang Pendidikan dan Budaya

1. Lomba Mewarnai

Lomba Mewarnai adalah salah satu program kerja tambahan, program yang dititik beratkan pada seni dan kreatifitas anak melalui media gambar yang diwarnai, program ini bertujuan untuk mengurangi guncangan jiwa yang di akibatkan tsunami selat sunda dan membuka arena bermain yang menyenangkan melalui permainan-permainan yang mempertajam serta mengasah otak anak.
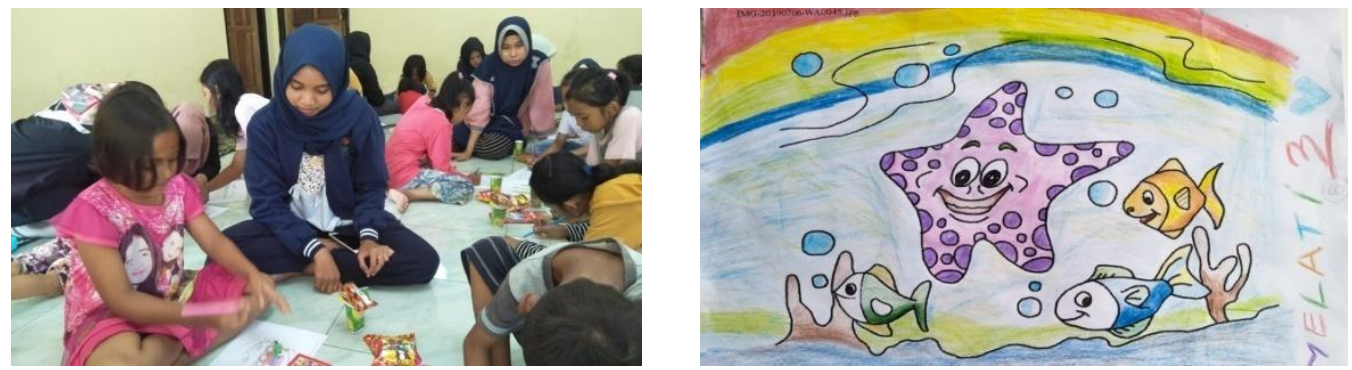

Gambar 7

Lomba Mewarnai

\section{KESIMPULAN}

Dari program kuliah PKM 2020 yang berlangsung selama lima minggu yang berlangsung di Desa Caringin, Kecamatan Labuan, Pandeglang Banten yang di mulai dari observasi lapangan dan pelaksanaan program sampai dengan pembahasan program maka dapat disimpulkan sebagai berikut :

1. Pelaksanaan program PKM 2020 dapat terlaksana dengan baik, hal ini tidak terlepas dari dukungan para pihak terutama pemerintahDesa Caringin, Kecamatan Labuan, Pandeglang Banten, masyarakat dan instansi terkait serta partisipasi .

2. PKM 2020 merupakan suatu usaha yang dilakukan untuk meningkatkan pengetahuan dan keterampilan serta pengalaman untuk menjadi bekal bagi mahasiswa, masyarakat umum, dan para penegak hukum yang terkait. 
3. Dengan adanya PKM 2020 dosen dan mahasiswa dapat mengenalkan ilmu dan IPTEK yang mahasiswa miliki kepada masyarakat serta mahasiswa dapat mempersiapkan diri menjadi pemimpin sesuai dengan tujuan Tri Dharma Perguran Tinggi.

4. Dengan adanya PKM dosen dan mahasiswa dapat pengalaman melalui interaksi dengan masyarakat serta kegiatan real pembangunan di daerah Desa Caringin sehingga dapat memperluas wawasan dan kedewasaan.

5. PKM merupakan bagian integeral yang mencakup kegiatan latihan belajar dan publikasi kepada masyarakat dan kegiatan yang bertema pendidikan lainnya.

\section{UCAPAN TERIMA KASIH}

Ucapan terima kasih disampaikan kepada:

1. Aparatur Desa Caringin, Kecamatan Labuan, Pandeglang Banten yang telah membantu dan memfasilitasi tempat dan masyarakat dalam kegiatan PKM ini;

2. Rektor Universitas Bina Bangsa yang telah memfasilitasi dan memberikan dukungan financial sehinggankegiatan PKM ini bisa terselenggara.

\section{DAFTAR PUSTAKA}

Haas, J. Eugene, Robert W. Kates, and Martyn J. Bowden. (1977). Reconstruction Following Disaster. Cambridge: MIT Press.

Johnson, Laurie A \& Olshansky, Robert B (2017). After Great Disasters: An In-Depth Analysis of How Six Countries Managed Community Recovery.

Pardede T., \& Tetsuo, K. (2007). Planning for post-disaster recovery: lesson from Aceh post-tsunami recovery. Department of urban engineering, University of Tokyo. Retrieved, February 2012 from http://rdarc.itakura.toyo.ac.jp/webdav/ask/public/ACP2007/togu.pdf

https://bpbd.bantenprov.go.id/ 